\section{Itinerários terapêuticos face à hipertensão arterial em famílias de classe popular}

\author{
Experience with treatment of high blood pressure \\ in low-income families
}

1 Universidade Federal da Bahia, Salvador, Brasil.

2 Universidade Federal do Recôncavo da Bahia, Santo Antônio de Jesus, Brasil.

Correspondência

L. A. B. Trad

Instituto de Saúde Coletiva, Universidade Federal da Bahia.

Rua Basílio da Gama s/n, Salvador, $B A$ 40110-040, Brasil. trad@ufba.br

\begin{abstract}
In order to properly understand high blood pressure $(H B P)$, or arterial hypertension, it is important to examine the influence of knowledge and beliefs associated with the condition, as well as the resources available for its treatment. This study analyzes the treatment experiences of three low-income extended families that include members with HBP. The study investigated the various alternatives that were adopted, determinants of choices, evaluation of the services used, and the impact of interaction with health services on care in the home. An ethnographic study was performed in a low-income neighborhood in Salvador, Bahia State, using direct observation and semi-structured interviews with key informants in home and institutional settings. The study found that the treatment experiences of the participating families did not follow a rigid pattern, but were influenced by prior experiences with hypertension and other diseases, available social support, and conditions in the formal health care system available in the neighborhood. The study also detected a grasp and adaptation of technical health knowledge by families.
\end{abstract}

Hypertension; Therapeutics; Low-Income Population; Cultural Anthropology
Leny Alves Bonfim Trad 1 Jeane Saskya Campos Tavares 2 Carla Silva Soares 1 Rachel Coelho Ripardo ${ }^{1}$

\section{Introdução}

A hipertensão arterial sistêmica (HAS) é uma condição clínica caracterizada por níveis de pressão arterial elevados e sustentados. O critério clínico para definir HAS em indivíduos acima de 18 anos corresponde a níveis tensionais iguais ou maiores que $140 \mathrm{mmHg}$ x $90 \mathrm{mmHg} 1$. É considerada uma doença assintomática, de evolução clínica lenta que, sem tratamento adequado, pode ter conseqüências graves, comprometendo a qualidade de vida do portador 2 . É uma das mais importantes causas de co-morbidade, sendo um fator de risco para desenvolvimento de doença arterial coronariana, acidente vascular cerebral, doença vascular periférica, insuficiência renal e insuficiência cardíaca congestiva, dentre outras 3,4 .

São reconhecidos os seguintes preditores sociodemográficos significativos para a hipertensão: idade, nível econômico na infância, trabalho, número de filhos e economia familiar. Aspectos intrapsíquicos como lócus de controle externo, indefensão aprendida e baixa auto-eficácia percebida sobre a própria saúde estariam relacionados à hipertensão nas classes mais baixas. A percepção relativa da pobreza também influenciaria os índices de hipertensão, especialmente entre indivíduos que experimentaram uma queda no seu padrão socioeconômico ${ }^{5}$.

A despeito dos componentes sociais envolvidos nessa problemática, as políticas públicas 
no Brasil têm priorizado o tratamento medicamentoso da HAS. Como indica a literatura 6,7,8,9, a baixa adesão da população a essa abordagem demonstra a necessidade de se considerarem os diversos aspectos psicossociais envolvidos, não tanto na etiologia quanto nos aspectos relativos ao tratamento dessa doença.

Estudos brasileiros sobre a HAS destacam a influência familiar no desenvolvimento dos principais fatores de risco $3,8,9,10$. Os significados atribuídos a "problemas emocionais" de origem familiar são apontados como uma importante fonte do descontrole da doença ${ }^{11}$. Os meios de prevenção e tratamento, assim como as informações disponibilizadas para as famílias de portadores, são fundamentais no controle da doença 3 .

O comportamento e as escolhas das famílias no enfrentamento da hipertensão arterial são abordados, neste estudo, com base na noção de itinerário terapêutico. Esse termo designa o conjunto de processos empreendidos pelos indivíduos e grupos na busca de tratamento, não necessariamente nas esferas institucionais, a partir da constatação de uma desordem ${ }^{12}$. Devem ser consideradas nesse processo "as etapas de elaboração do diagnóstico e de tratamento adotadas pelo paciente, analisando as interações entre os diferentes atores (doente, família, comunidade, categorias de curadores) envolvidos ao longo da evolução da doença" 13 (p. 34).

Alves \& Souza 14 reconhecem diferenças significativas entre os enfoques abordando o tema apresentados no decorrer da segunda metade do século XX. Os primeiros trabalhos (1950-1960) centravam-se no comportamento do enfermo (illness behavior) e apontavam a avaliação do custo-benefício como determinante nas escolhas dos indivíduos. Esse enfoque foi bastante criticado por apresentar uma visão utilitarista e reducionista. Uma segunda vertente, também apoiada no comportamento do enfermo, focalizou as determinações culturais, típicas de minorias étnicas, na utilização de serviços de saúde. A despeito de sua contribuição para a compreensão dos fatores extrabiológicos das doenças, esses estudos foram bastante criticados por suas deficiências teórico-metodológicas.

A partir de 1970, os estudos sobre itinerários terapêuticos voltaram-se para os aspectos cognitivos e interativos. No que diz respeito aos primeiros, enfatizava-se que a busca aos serviços estaria condicionada aos significados atribuídos à enfermidade, seja na relação com a normalidade ou potencial de incapacidade, seja no que concerne à relevância atribuída ao distúrbio. A análise interativa, por sua vez, valorizava o papel das redes sociais na conformação do itinerário terapêutico.
Alves e Souza 14 destacam, ainda, os modelos explicativos, particularmente a concepção sistêmica de Kleinman 15, na qual se articulam “diferentes elementos ligados à saúde, doença e cuidados com a saúde, tais como: experiência dos sintomas, modelos específicos de conduta do doente, decisões concernentes a tratamento, práticas terapêuticas e avaliação de resultados" 14 (p. 128). Esses autores concluem sua análise apontando uma limitação do ponto de vista teóricoconceitual:

"As diversas teorias que abordam essa temática, presas a princípios de caráter nomológico-dedutivo, procuram desenvolver, em diversos níveis, argumentos baseados em premissas previamente estabelecidas para explicar as ações individuais. Assim na busca de uma generalidade, de uma suposta ordem, os estudiosos do itinerário terapêutico subsumiram os complexos processos de escolha de um tratamento a um modelo de conhecimento científico que reduz as ações humanas a uma 'geometria do vivido"” 14 (p. 136).

O itinerário terapêutico envolve hábitos, o acaso, os atos impensados, não apresentando, assim, um modelo ou padrão dentro do qual possam ser enquadrados os processos de escolha: “'fazer sentido' para o indivíduo, e esta pode ser a forma de racionalização empreendida: a lógica permeada por conhecimentos e hábitos culturais... negociado nas relações sociais e legitimado pela sociedade" 16 (p. 126). Gerhardt 17, ao analisar os itinerários terapêuticos em situação de pobreza, observa que a automedicação costuma ser o primeiro recurso diante de problemas "leves" neste contexto. Nos episódios graves, as famílias costumam recorrer imediatamente ao atendimento médico na rede pública. A autora salienta que as experiências e as informações acumuladas pela família, aliando racionalidades biomédicas e populares de saúde, vão influenciar na avaliação da gravidade dos episódios. As estratégias e os discursos desenvolvidos pelos indivíduos frente ao adoecimento são elaborados baseando-se em instituições, representações coletivas e relações sociais reinterpretadas em função das suas "situações de vida" 17.

Esta pesquisa analisa itinerários terapêuticos de famílias de classe popular que têm hipertensos entre seus membros. Foram investigados os processos de escolha, utilização e avaliação dos serviços de saúde disponíveis no bairro; por fim, analisou-se em que medida a interação das famílias com os serviços formais de saúde repercute sobre as práticas de cuidado desenvolvidas no contexto familiar. 


\section{Metodologia}

O estudo etnográfico foi realizado no bairro da Boca do Rio, na cidade de Salvador, Estado da Bahia, um território que pode ser caracterizado como um bairro "dividido", no qual os investimentos públicos e recursos urbanos são desigualmente distribuídos 18 . A região periférica do bairro apresenta uma infra-estrutura precária, sendo essencialmente o lócus da reprodução sócioespacial da população de baixa renda.

O Distrito Sanitário da Boca do Rio conta com duas unidades básicas de saúde (UBS) e um Centro de Saúde com pronto atendimento de emergência. Os serviços oferecidos variam entre as unidades. Alguns serviços, como clínico geral, ginecologia, pediatria, programa de atenção a hipertensos e diabéticos, e agentes comunitários de saúde (ACS) foram referidos nas três unidades.

$\mathrm{O}$ bairro foi se formando e se expandindo por meio de "invasões" sucessivas. Seus moradores convivem cotidianamente com a violência e/ou o desemprego, entre outras mazelas sociais. A área selecionada para o estudo em profundidade é denominada Sibéria (nome fictício) e foi indicada por moradores e profissionais de saúde como um dos lugares mais perigosos e desassistidos do bairro.

O estudo de campo durou cerca de um ano e meio, com curtos períodos de afastamento (período de festas ou de agravamento do quadro de violência local). O estudo focalizou as trajetórias ou itinerários de famílias de classes populares no enfrentamento de problemas de saúde. O trabalho etnográfico se concentrou na observação, mediada por entrevistas semi-estruturadas, de espaços domiciliares, assim como de contextos institucionais e comunitários, particularmente aqueles vinculados ao sistema de saúde ou a processos de controle e participação social em Sibéria. No escopo deste artigo, são apresentados os achados referentes a três famílias que têm em comum as seguintes características: enquadraremse na modalidade de família extensa; possuírem renda familiar per capita inferior a um salário mínimo; possuírem ao menos um membro com hipertensão arterial crônica. Vale destacar a proximidade geográfica e afetiva entre as três famílias que, há pelo menos duas décadas, formavam, entre elas, uma rede de ajuda mútua.

O conjunto de resultados apresentados, além de incluir os dados registrados em diário de campo, fruto da observação sistemática, reflete a interlocução formal com 23 informantes, sendo: dois líderes comunitários, três gerentes de unidades de saúde, dois ACS que atendiam a essa área e imediações, três representantes da prefeitura municipal (representante da secreta- ria de assistência social, coordenadora da administração regional IX e vice-coordenadora do distrito sanitário da Boca do Rio) e 13 membros de três famílias moradoras da região. À exceção dos representantes da prefeitura e dos gerentes das unidades, todos eram moradores da Boca do Rio desde que nasceram ou há pelo menos 10 anos.

A família Pires distribuía-se em sete diferentes unidades domiciliares, no entanto havia intensa convivência intergeracional. D. Isaura, a principal informante e cuidadora dessa família, morava no bairro há 37 anos e era casada com Sr. Isaías, com quem teve seis filhos. Dentre esses, os principais cuidadores de Isaura e Isaías (portadores de HAS) eram Irton (36 anos), Inaldo (35anos) e Isa (26 anos). Isaura é irmã de Lafaiete, Leila e Lorena (irmã de criação), que formam o grupo apresentado a seguir.

Durante o trabalho de campo, três gerações da família Lopes conviviam na mesma unidade domiciliar e as responsabilidades de manutenção financeira e administrativa eram divididas entre Ludmila, Lorena e Leila. O acesso ao grupo se deu por intermédio de Ludmila (44 anos), que morava com dois de seus filhos, Liliane (20 anos) e Leonardo (12 anos), com Lafaiete (71 anos), seu pai "de criação", e suas tias, Lorena (59 anos) e Leila (66 anos), esta última considerada "mãe de criação" de Ludmila. Moradores de outras unidades foram indicados como membros da família: Leandro (28 anos) filho mais velho de Ludmila, e Lúcia (31 anos), filha de Leila. Em relação à saúde, Ludmila e Lorena dividiam as responsabilidades dos cuidados, pois todos os membros com mais de 40 anos tinham desenvolvido HAS e, na geração anterior, foram relatadas mortes e limitações físicas associadas a esta doença.

A família Rodrigues era composta por membros de três gerações distribuídos em quatro unidades domiciliares, e formou-se a partir de separações e novas uniões de Ronaldo (60 anos). Esse morava com dois dos seus seis filhos, Rodrigo (22 anos) e Robson (29 anos), que eram seus principais cuidadores e mantinham vínculos afetivos mais intensos. Faziam parte da família, ainda, Rosa (46 anos), ex-esposa de Ronaldo; Roberto (28 anos) e Rômulo (30 anos), seus filhos mais velhos; Reinaldo (8 anos) e Renan (6 anos), filhos de um relacionamento de Ronaldo com Renata (27 anos). Esse grupo não tinha experiência com adoecimentos considerados graves, exceto o caso de Ronaldo, que havia sofrido um acidente vascular cerebral (AVC) em decorrência da HAS cerca de dois meses antes do início de sua participação no estudo.

A produção de dados foi realizada em três fases. A primeira consistiu na observação no âmbito institucional e entrevistas com gestores, profis- 
sionais da rede formal e usuários dos serviços, a fim de traçar um perfil da rede formal de atenção à saúde disponível no bairro e explorar a interação entre os serviços e a comunidade. Na segunda fase se estabeleceu um contato mais intenso com a comunidade da Sibéria e seus moradores, especialmente os mais antigos ou lideranças comunitárias, propiciando a seleção das famílias para o estudo em profundidade, terceira etapa da pesquisa. Na etnografia com as famílias foram explorados os seguintes aspectos: a história da família e de sua inserção no bairro, a estrutura e dinâmica atual do grupo familiar, o histórico de adoecimento e cuidados com a saúde entre os membros, os itinerários terapêuticos desenvolvidos e a relação com os profissionais de saúde. As famílias foram acompanhadas por um período aproximado de oito meses. As entrevistas semiestruturadas foram gravadas e cuidadosamente transcritas. Todo o processo de observação foi acompanhado de registro sistemático em diário de campo, reconhecido como um instrumento fundamental no trabalho etnográfico, uma vez que nele são registrados percepções, questionamentos e informações que não podem ser obtidos por meio dos outros instrumentos 19 .

O processo de análise foi orientado pela antropologia interpretativa, buscando a apreensão dos significados implícitos ao comportamento dos sujeitos 20, reconhecendo, ao mesmo tempo, o contexto sociocultural e interativo no qual os sentidos são produzidos 21. Como estratégia complementar foram construídos genogramas familiares, descritos por Cerveny 22 como instrumentos de representação gráfica familiar que possibilitam a apreensão não só das gerações que compõem o sistema, como também da estruturação e dinâmica deste grupo.

$\mathrm{O}$ estudo obedeceu às determinações da $R \boldsymbol{e}$ solução $n^{o}$. 196/1996 do Conselho Nacional de Saúde (CNS), tendo sido submetido e aprovado pelo Comitê de Ética do Instituto de Saúde Coletiva, Universidade Federal da Bahia (ISC/UFBA). A fim de assegurar o anonimato dos participantes, todos receberam nomes fictícios. Também foram alterados os sobrenomes das famílias.

\section{Resultados e discussão}

Os itinerários terapêuticos: cuidados com a saúde e (im)possibilidades socioeconômicas

Na análise dos itinerários terapêuticos das famílias participantes, confirmou-se a proposição de Alves \& Souza 14 de que não há a priori neste processo a manifestação de uma unidade articulada, mas sim a tentativa consciente de remontar o passado com base no conhecimento atual. Articulam-se nesse processo, sistemas de significados associados a padrões de interações pessoais e das instituições sociais 15 .

Na família Pires, Isaura é a principal cuidadora e/ou orientadora dos cuidados prestados pelos filhos e noras aos netos. Evidenciou-se que se dispensa uma atenção maior às crianças: "criança é... em primeiro lugar". Os cuidados com os idosos referem-se prioritariamente à dieta: "só dispenso um pouquinho no sal e na gordura”. Entre os adultos também se cuida da alimentação, sobretudo dos que desenvolveram HAS.

Entre os filhos, Isaura aponta Inaldo, Isa e Irton como aqueles que mais se destacam nas práticas de cuidado em saúde. O primeiro é identificado como principal cuidador, juntamente com o pai, em casos de emergências de saúde. Isa, além de auxiliar nas emergências de saúde, também participa com auxílio material, "comprando coisas" a pedido da mãe. Irton auxiliava, sobretudo financeiramente, e por meio de serviços de pintura e pedreiro na casa dos pais.

As orientações incluem a utilização cotidiana de remédios que "descobre" em farmácias: "Eu quando vou na farmácia, eu fico assim olhando, sabe, pesquisando" (Isaura). Além desses, são recomendados chás, folhas, frutos secos e a Fitoterapia como alternativos ou complementares ao tratamento com remédios. Seguindo as recomendações de Isaura, a prática da automedicação é comum entre os membros da família, que defendem a necessidade de conciliar os dois tipos de tratamento, principalmente para a hipertensão.

Essa doença é referida como o problema de saúde mais comum não apenas da família, mas de todo o bairro, e associado, principalmente, ao envelhecimento. A HAS é reconhecida, nesse grupo, como uma "doença da família" devido ao número de membros portadores e por ter acometido diferentes gerações. Entre os adultos, o itinerário seguido para a resolução dos problemas de saúde de Isaura ganhou destaque nos relatos, devido aos papéis que ela desempenhava no grupo e ao impacto do seu adoecimento sobre a família Pires.

Em sua primeira crise hipertensiva, caracterizada por fortes dores de cabeça e vômito, Isaura foi conduzida pelo marido ao hospital onde o mesmo trabalhava. O fato de Isaías ser empregado da instituição e desta ser privada são considerados fatores determinantes para o atendimento imediato e de "boa qualidade" recebido por Isaura. Após esse primeiro episódio, Isaura foi atendida na unidade básica de referência do bairro e, posteriormente, encaminhada para um centro especializado em doenças cardiovasculares, 
em outro bairro, onde era acompanhada mensalmente. Pouco tempo depois, desconfiada da eficiência dos serviços prestados e da capacidade técnica dos profissionais do centro de saúde, ela voltou, por conta própria, a buscar atendimento na unidade do seu bairro:

“Todo mês quando eu ia fazer esse exame, do teste, eu tava com pressão alta. Diz ele, né. Quando eu chegava aqui a pressão tava normal (...). Passava no posto [Unidade César de Araújo], media, a pressão tava boa (...). Aí eu me aborreci, nunca mais eu fui".

Durante sua participação na pesquisa, utilizava medicação distribuída nessa UBS, no entanto, diante da falta constante de medicamentos, optava pelo uso contínuo da medicação prescrita em sua primeira crise. Também buscava atendimento em "postos" de candidatos a vereadores que funcionavam durante os períodos de campanha eleitoral, nos quais conseguia as guias para exames e consultas no centro de saúde de referência.

No caso de Isaías, constatou-se uma conduta diversa frente ao mesmo problema de saúde. Sentindo-se tonto e com forte enjôo, foi levado por Isa e Ivan para a emergência do centro de saúde da região, onde ficou internado durante a noite. Um dia após a internação, foi levado por Isaura a um "posto de saúde" de vereador, ao qual Isaías continuou se dirigindo posteriormente. Devido ao funcionamento intermitente desse "posto", que fechava quando o vereador não era reeleito ou não tinha verbas, Isaías optou por ser acompanhado na Unidade César de Araújo.

Dentre os membros dessa família, apenas Isabela relatou não buscar assistência médica formal quando está doente, por causa de sua crença religiosa. Não faz uso de remédios ou chás, pois como evangélica, ela acredita na cura pela oração. Quando se sente doente, dirige-se à igreja e faz orações em casa, o que afirma ajudar bastante em sua recuperação. No entanto, quando avalia o quadro como grave, não hesita em ir para a emergência.

De modo geral, a família utiliza as mesmas unidades e hospitais de referência conforme sua percepção de necessidade e gravidade da doença, assim como da acessibilidade. Até o ano de 1997, utilizavam com frequência o hospital privado em que Isaías trabalhava. Com sua aposentadoria, passaram a recorrer a hospitais públicos (um hospital geral e uma maternidade) em casos de emergência ou partos. Com a inauguração do 12 o centro no bairro, passaram a buscar atendimento preferencialmente nesta unidade, nas emergências, recorrendo a UBS local ou aos "postos dos vereadores" para o atendimento ambulatorial.
Na família Lopes, Ludmila foi identificada como a principal cuidadora. Corroborando a literatura sobre o tema, os itinerários terapêuticos da família guardavam clara associação com a avaliação de gravidade dos problemas de saúde que afetavam o grupo. Usualmente, tratavam de problemas "leves" em casa, por meio de mudança na alimentação e da chamada "medicina alternativa"; os "graves" implicavam busca de atendimento no sistema formal de saúde. Associados a esses tratamentos, havia a participação em grupos de orações na igreja e/ou na residência dos doentes.

Nesse grupo, observou-se a valorização do saber médico especializado e do sistema formal de saúde.

A busca preferencial pelo sistema formal para cuidados com a saúde (principalmente das crianças) era uma prática compartilhada por membros de diferentes gerações, sendo recorrente a alusão à satisfação com o atendimento prestado. Nessa família eram priorizados os cuidados profissionais nos diversos tipos de doença que os atingiram ("asma”, "doença de pele", "problemas de circulação”, "problemas de vista”). Contudo, como se discutirá mais adiante, a disposição em procurar o serviço de saúde de forma regular variava no grupo.

Em relação à HAS, identificada em pelo menos três gerações, todos se mostraram informados acerca dos cuidados necessários, principalmente fazer consulta médica periódica, uso de medicamentos e controle alimentar evitando-se "sal, gordura, fritura, carne" (Leila).

No entanto, o entendimento dos participantes sobre o acompanhamento médico divergia, pois enquanto Ludmila e Lorena buscavam com freqüência a rede formal, Leila e Lafaiete evitavam contatos com profissionais de saúde, principalmente médicos, optando pelo controle alimentar como principal forma de tratamento. Leila justifica esse comportamento por não perceber sintomas da HAS:

"E quando me sentir muito mal, vou no posto, né, se eu tiver com problema, se verificar que a pressão está muito alta, eu vou no posto. Às vezes eu demoro até de ir no posto". Lorena fala que'- ah, você tem que ir no posto', - oh Lorena, eu não estou sentindo nada, eu vou pro posto. A gente só vai quando tá sentindo, mas eu não sinto" (Leila).

Leandro também evitava contatos regulares com profissionais de saúde e, assim como Leila, a busca pelo sistema formal estava condicionada à percepção de gravidade do seu estado clínico:

"Ele só vai no médico quando tá assim, com algum problema. Que agora ele tá com um problema seríssimo, nas vistas, que ele já teve, há muitos anos atrás, uma inflamação no olho e essa infla- 
mação causou muitos problemas nele. E agora, depois de muitos anos, tá voltando de novo. (...) Na época, ele tava trabalhando, na época, tinha um convênio, o convênio assumiu todos os, o tratamento. Ele fez um tratamento de retina. Mais ou menos, tem na faixa de uns quinze anos, que aconteceu isso. Mas a médica disse que ele tinha que, de vez em quando, uma vez no ano, procurar um oftalmologista. Ele não ligou. Foi pra Vitória da Conquista com problema, nunca ligou. Agora tá voltando todos os sintomas, agora que ele tá desesperado e correndo atrás".

Além de consultas médicas, Ludmila e Lorena participavam de palestras e caminhadas organizadas pelo serviço de atenção a hipertensos e diabéticos da UBS local. Essa participação era considerada fundamental, principalmente por Ludmila, pois, além de ensinarem receitas de alimentos para hipertensos, ali encontrava espaço para dirimir dúvidas, como afirma a própria:

"O posto oferece pra gente é palestra sobre hipertensão, sobre diabete. Agora mesmo teve uma menina do posto (...) desse César de Araújo, me convidou pra palestra segunda-feira, sobre esses problema de hipertensão e diabete, agora vai ser aí na Kolpe, 2 horas da tarde. Toda vez que tem, eu sempre vou porque eu gosto, porque sempre eu venho tirando assim (...) tem umas perguntas que eu fico em dúvida e eu gosto de perguntar pra esclarecer".

Os membros dessa família reconhecem que seus comportamentos em relação à saúde não são comuns no contexto em que vivem. De modo geral, segundo esses participantes, "as pessoas que não têm, assim, os cuidado que a gente tem, assim, de (...) de cautela de boca, come tudo" (Leila). E quanto à busca por informações especializadas e freqüência nas atividades da UBS: "Poucos vão pra palestra, às vezes, porque tudo tem, né, um lado bom e um lado ruim. Mas muitas pessoas vão e não ficam até o fim da palestra" (Ludmila).

$\mathrm{O}$ abandono do tratamento profissional foi relatado apenas em uma situação, na qual este foi reconhecido como ineficaz. Foi o caso do problema de pele de Leonardo: "o médico disse que não tinha tratamento pra ele, que a pele dele antigamente, todo ano, abria um tipo de ferida". Foram necessários anos de insucesso com diferentes tratamentos alopáticos até que aderissem totalmente ao tratamento fitoterápico.

Na família Rodrigues, por sua vez, não havia o hábito de freqüentar consultas médicas ou utilizar o sistema formal sistematicamente, exceto para as crianças da segunda união. O derrame de Ronaldo, resultado da HAS, foi apontado, por todos, como o único problema de saúde grave na história familiar. O diagnóstico de HAS deuse, inesperadamente, durante exames para re- novação da carteira de habilitação, no entanto, Ronaldo não buscou tratamento, pois segundo ele "não tinha sintoma nenhum". As graves repercussões da doença se manifestaram após um ano: "do nada, assim, fui dormir, e quando acordei de manhã tava todo desequilibrado, sem forças pra nada, não levantei, nada, fiquei na cama" (Ronaldo).

As medidas emergenciais para socorrer Ronaldo foram tomadas pelos filhos Robson, Rodrigo e Reinaldo e por sua ex-mulher e vizinha Renata. A ação mais importante foi acionar o Serviço de Atendimento Médico de Urgência (SAMU), que, segundo Renata, "não veio, demorou, porque eles fazem muita pergunta. Aí eles demoraram de vir. Aí levou, um vizinho pegou, levou de carro". Ronaldo foi levado à emergência de um centro de saúde, na companhia de Rodrigo, onde foi examinado e encaminhado para diferentes hospitais.

Segundo Ronaldo, o período de busca por vaga nos hospitais durou cerca de três a quatro horas. Nesse intervalo, foram realizadas radiografias, no entanto, apesar da gravidade do quadro, ele não foi internado, mas apenas orientado a mudar a dieta. Após esse episódio, Ronaldo manteve o acompanhamento médico, além de receber cuidados diferenciados dos filhos e dos vizinhos. Algumas das repercussões do derrame relatadas pelos membros das famílias foram: paralisia de um lado do corpo, dificuldade de locomoção, amnésia e déficit auditivo. Para Ronaldo, a principal repercussão do seu adoecimento foi a impossibilidade de trabalhar, o que agravou o empobrecimento da família e, conseqüentemente, comprometeu os cuidados necessários à sua nova condição, pois os filhos tiveram de fazer mais "bicos".

O apoio dos vizinhos foi considerado fundamental para o sucesso do tratamento de Ronaldo no seu período crítico. Eles se responsabilizaram pelas tarefas domésticas, antes desenvolvidas por Ronaldo, além de doarem alimentos que consideravam importantes para a sua recuperação. É necessário salientar que, nesse grupo, os vizinhos (principalmente os membros das famílias Pires e Lopes) não apenas cuidavam, mas orientavam as decisões na constituição dos itinerários terapêuticos. A participação intensa da vizinhança foi especialmente requerida em virtude do desconhecimento dos filhos de Ronaldo sobre seu quadro de saúde e da insegurança destes quanto às decisões a serem tomadas no cuidado do pai.

Pode-se supor que a inexperiência em lidar com situações de adoecimento grave tenha contribuído para projetos de ação pouco elaborados e menos fundamentados na experiência pessoal ${ }^{14}$. Associado a isso, a inexistência de mu- 
lheres na rede familiar mínima, centrais nas atividades de cuidado à saúde em nossa sociedade 23 , pareceu ser mais um elemento dificultador do desenvolvimento dos itinerários terapêuticos desse grupo.

Por outro lado, nas famílias Pires e Lopes, características estruturais e dinâmicas, combinadas às experiências prévias com a hipertensão, pareceram facilitar a constituição dos itinerários terapêuticos, concordando com a literatura a respeito 14,16. Dessa forma, a experiência com doenças foi relevante na adoção de comportamentos preventivos, na identificação de sintomas, na eleição dos sistemas de ajuda e tratamento e na observância a prescrições médicas. Contrariando autores como Saraiva et al. 3 , seus membros não se encontravam desassistidos enquanto cuidadores, ao contrário, tinham amplo conhecimento quanto à etiologia e tratamento da doença.

Considerando-se os relatos dessas famílias, a HAS foi compreendida como um problema de saúde grave por suas repercussões (morte e limitações físicas). Esse status contribuiu para que, nesses casos, a maior parte dos seus membros aderisse ao tratamento no sistema formal e associasse ao tratamento medicamentoso mudanças no comportamento alimentar (em todos os grupos) e uso de folhas e chás (famílias Pires e Lopes). Por fim, em relação aos itinerários e cuidados com a saúde, especificamente no tratamento da HAS, o recurso à automedicação foi enfatizado apenas na família Pires.

Confirmando os pressupostos de Kleinman 15, as crenças, expectativas e comportamentos relativos ao indivíduo doente (illness), neste caso o hipertenso, sua família e a rede social diferem do modelo explicativo profissional (disease). Em realidade, os casos investigados confirmam os achados de Firmo et al. 11 de que os portadores de HAS podem apresentar um discurso aparentemente semelhante ao biomédico, porém com diversas reinterpretações, especialmente no que diz respeito ao tratamento.

\section{Interação com o sistema formal de saúde}

Não foi necessário o esgotamento das competências e recursos individuais ou familiares para que as famílias recorressem ao sistema formal de saúde. Dado que contraria os achados presentes em outros estudos 15,24. Essa recorrência aos serviços de saúde não reflete, necessariamente, uma satisfação com os serviços encontrados. As unidades de saúde são percebidas pelas famílias estudadas como serviços burocratizados, marcados por problemas administrativos e que não atendem às necessidades da população. Essa avaliação foi compartilhada também pelos profissionais de saúde e outros usuários, e confirmada por meio da observação no campo. A UBS de referência em Sibéria tinha espaço e número de profissionais insuficientes para a demanda local, assim como falhas na distribuição de medicamentos. Além disso, passava por períodos de greve dos ACS por falta de pagamento de salários.

Constatou-se que a relação entre os moradores de Sibéria e os profissionais de saúde era marcada pela desconfiança mútua. Os moradores responsabilizavam os profissionais de saúde pelo mau funcionamento da UBS e referiam-se a estes e aos gestores como "preguiçosos e desatenciosos". Em relação a esse último aspecto, os participantes indicaram a necessidade de adotar estratégias como "agradar as pessoas", "não brigar” e "não reclamar", como forma de viabilizar os atendimentos. No que se refere à abordagem adotada pelos profissionais nas consultas, os relatos indicaram que, assim como comprovado por Souza \& Garnelo 25 , não eram valorizadas as dimensões do adoecer de ordem não biológica, incluindo os significados atribuídos pelos usuários aos sintomas, bem como, os problemas de ordem familiar ou financeira que pudessem impactar sobre o seu estado de saúde. Além disso, não se incentivava a autonomia do indivíduo ou seu poder de tomar decisões em questões inerentes à sua saúde.

Os profissionais, por sua vez, apontavam como fatores que dificultavam ou inviabilizavam seu trabalho (e que pareciam contribuir para o desinteresse pelos problemas do bairro e da comunidade) características "próprias" da população: preguiça, agressividade e desinteresse. Alguns depoimentos adicionavam a essa lista a inabilidade de autocuidado da população.

A percepção sobre os principais problemas de saúde na região diferia entre a comunidade e os profissionais. Enquanto a população local destacava a violência e a ausência de saneamento básico na região, gestores, gerentes e profissionais enfatizavam a necessidade de controle de natalidade entre adolescentes, prevenção de infecção por DST/HIV ou de câncer de cabeça e pescoço, e se referiam à violência como mais um problema de saúde (não o mais relevante).

No discurso dos representantes dos serviços de saúde as dificuldades socioeconômicas da população não eram enfatizadas. Prevalecia o entendimento de que o convívio com a miséria e a violência intra e extrafamiliar demandava capacidade adaptativa. As famílias eram constantemente responsabilizadas pelos profissionais por serem "incontinentes" com suas crianças, ignorantes e "pouco aderentes" às orientações e aos cuidados oferecidos pelos serviços. 
Os agentes de saúde, contudo, apresentavam uma visão dissonante. Reconheciam as dificuldades das equipes de saúde em apoiar a população local, mas, apontavam a deficiência de infraestrutura da rede como um fator determinante neste processo. Jonas, ACS que acompanhava a comunidade estudada, destacou a necessidade de melhorar as condições da UBS para que houvesse adesão, e evitava personalizar ou culpabilizar a população por seu estado de saúde:

"A gente vai na área, conversa com as pessoas, orienta, elas vêm pro posto (...) e chega aqui se ela não tiver (...) não for bem atendida, aí ela já cria mais dificuldade de vir (...) já fica mais receosa em vir , porque tem que vir de madrugada, aí fica com medo da violência e tudo (...)".

Além da avaliação sobre a gravidade do problema, as dificuldades relacionais e/ou de acesso às consultas e medicamentos contribuíram para que as famílias adequassem as orientações recebidas sobre o tratamento da HAS segundo suas experiências e recursos pessoais. Confirma-se, sobretudo, que as escolhas terapêuticas não são definitivas ou incontestáveis, sendo fundamental o critério de eficácia 26 aliado às condições objetivas de acesso 11,27.

\section{Considerações finais}

Os itinerários das famílias investigadas foram mediados, principalmente, por características estruturais e dinâmicas dos grupos, pelas experiências prévias com a hipertensão e outras doenças, pelo suporte social oferecido pela vizinhança e pelas condições de atendimento do sistema formal no bairro. A compreensão sobre itinerários terapêuticos deve considerar, portanto, tanto a disponibilidade de serviços de saúde (formais e informais) e a forma como estes são utilizados, quanto as possibilidades socioculturais que viabilizam a elaboração e implementação das trajetórias 27. É importante reconhecer que os pacientes e suas famílias utilizam e manipulam de maneira eclética todos os recursos e alternativas terapêuticas disponíveis 13 .

Constatou-se a importância dos serviços de saúde na produção de conhecimento e comportamentos vinculados à hipertensão arterial. Com base no diagnóstico e prescrições fornecidas pelos serviços, são referidas mudanças de comportamento sintonizadas com as recomendações médicas. Ao mesmo tempo, seguindo uma lógica bidirecional, encontramos processos de ressignificação das orientações recebidas e o engajamento de membros das famílias analisadas em atividades de difusão de informações sobre a hipertensão, contribuindo para a disseminação destes conhecimentos na comunidade. Convém destacar que o reconhecimento das interfaces simbólicas e práticas entre a racionalidade biomédica e a popular apresenta-se como uma via estratégica para a concretização das práticas de promoção da saúde 28 .

De fato, apesar da forte valorização do sistema formal e do conhecimento médico especializado, observada nas três famílias, foi recorrente a alusão à adoção de práticas domésticas complementares no enfrentamento da hipertensão. Evidencia-se assim que a interação entre os sistemas de auto-atenção e os sistemas biomédicos ocorre, a despeito da aceitação ou não do sistema dominante; sendo recomendável, portanto, que se efetive na rotina dos sistemas biomédicos a articulação com os sistemas de auto-atenção 28 . 


\section{Resumo}

Na compreensão sobre a hipertensão arterial sistêmica (HAS) é importante considerar a influência dos conhecimentos e crenças associados à doença, bem como, os recursos disponíveis para o seu tratamento. Este trabalho analisa itinerários terapêuticos de três famílias de classe popular do tipo extensa que possuíam portadores de HAS. Investigou-se as alternativas adotadas, os de terminantes das escolhas, a avaliação sobre os serviços utilizados e os reflexos da interação com os serviços no cuidado doméstico. Foi realizado um estudo etnográfico em um bairro popular de Salvador por meio de observação e entrevistas semi-estruturadas com informantes em espaços domiciliares e institucionais. Constatou-se que os itinerários das famílias participantes não seguiam um padrão rígido, sendo influenciados pelas experiências prévias com a hipertensão e outras doenças, pelo suporte social disponível e pelas condições do atendimento do sistema formal no bairro. Observou-se, também, a apropriação e adaptação do conhecimento técnico de saúde pelos grupos familiares.

Hipertensão; Terapêtica; População de Baixa-Renda Antropologia Cultural

\section{Colaboradores}

L. A. B. Trad definiu o desenho da pesquisa e o marco teórico, coordenou todas as etapas da pesquisa e redigiu as partes principais do artigo. J. S. C. Tavares contribuiu na construção do marco teórico e metodológico do estudo, conduziu parte significativa da coleta de dados e redigiu segmentos importantes do artigo. C. S. Soares contribuiu no processo de refinamento teórico-metodológico, participou ativamente do processo de coleta e análise de dados, e redigiu segmentos complementares do artigo. R. C. Ripardo contribuiu no processo de refinamento teórico-metodológico, participou ativamente do processo de coleta e análise de dados, e redigiu segmentos complementares do artigo.

\section{Agradecimentos}

Agradecemos a contribuição de Maria Ivana Guerra e João Marcos de Oliveira na realização do trabalho de campo.

\section{Referências}

1. Cesarino CB, Cipullo JP, Martin JFV, Ciorlia LA Godoy MRP, Cordeiro JA, et al. Prevalência e fatores sociodemográficos em hipertensos de São José do Rio Preto - SP. Arq Bras Cardiol 2008; 91:31-5.

2. Toledo MM, Rodrigues SC, Chiesa AM. Educação em saúde no enfrentamento da hipertensão arterial: uma nova ótica para um velho problema. Texto \& Contexto Enferm 2007; 16:233-8.

3. Saraiva KRO, Santos ZMSA, Landim FLP, Teixeira AC. Saber do familiar na adesão da pessoa hipertensa ao tratamento: análise com base na educação popular em saúde. Texto \& Contexto Enferm 2007; 16:263-70

4. Cavalini LC, Chor D. Inquérito sobre hipertensão arterial e décifit cognitivo em idosos de um serviço de geriatria. Rev Bras Epidemiol 2003; 6:7-17.
5. Gandarillas MA, Câmara SG, Scarpato H. Estressores sociais da hipertensão em comunidades carentes. Psicol Reflex Crit 2005; 18:62-71.

6. Pugliese R, Zanella MA, Blay SL, Plavinik F, Andrade MA, Galvão R. Eficácia de uma intervenção psicológica no estilo de vida para redução do risco coronariano. Arq Bras Cardiol 2007; 89:225-30.

7. Lessa I, Magalhães L, Araújo MJ, Almeida Filho N, Aquino E, Oliveira MMC. Hipertensão arterial na população adulta de Salvador (BA) - Brasil. Arq Bras Cardiol 2006; 87:747-56.

8. Mano GMP, Pierin AMG. Avaliação de pacientes hipertensos acompanhados pelo Programa Saúde da Família em um centro de saúde escola. Acta Paul Enferm 2005; 18:269-75. 
9. Simonette JP, Batista L, Carvalho LR. Hábitos de saúde e fatores de risco em pacientes hipertensos. Rev Latinoam Enferm 2002; 10:415-22.

10. Mendes MJFL, Alves JGB, Alves AV, Siqueira PP, Freire EFC. Associação de fatores de risco para doenças cardiovasculares em adolescentes e seus pais. Rev Bras Saúde Matern Infant 2006; 6:49-54.

11. Firmo JOA, Lima-Costa MF, Uchoa E. Projeto Bambuí: maneiras de pensar e de agir de idosos hipertensos. Cad Saúde Pública 2004; 20:1029-40.

12. Augé M. Ordre biologique, ordre social: la maladie, forme élementaire de l'évènement. In: Augé $\mathrm{M}$, Hezlich C, editors. Le sens du mal. Anthropologie, histoire et sociologie de la maladie. Paris: Éditions de Archives Contemporaines; 1984. p. 35-91.

13. Buchillet DA. A antropologia da doença e os sistemas oficiais de saúde. In. Buchillet DA, organizador. Medicinas tradicionais e medicina ocidental na Amazônia. Belém: Edições Cejup; 1999. p. 21-44.

14. Alves PC, Souza IM. Escolha e avaliação de tratamento para problemas de saúde: considerações sobre o itinerário terapêutico. In: Rabelo $\mathrm{MC}, \mathrm{Al}$ ves PC, Souza IM, organizadores. Experiência de doença e narrativa. Rio de Janeiro: Editora Fiocruz; 1999. p. 125-38.

15. Kleinman A. Concepts and a model for the comparison of medical systems as cultural systems. Soc Sci Med 1978; 12:85-93.

16. Leite SN, Vasconcellos MPC. Negociando fronteiras entre culturas, doenças e tratamentos no cotidiano familiar. Hist Ciênc Saúde Manguinhos 2006; 13:113-28.

17. Gerhardt TE. Itinerários terapêuticos em situações de pobreza: diversidade e pluralidade. Cad Saúde Pública 2006; 22:2449-63.
18. Santos CA, Serpa ASP. Boca do Rio: um bairro dividido. In: Angelo S, organizador. Cidade popular - trama de relações socioespaciais. 1a Ed. v. 1. Salvador: EDUFBA; 2007. p. 43-66.

19. Cruz Neto O. O trabalho de campo como descoberta e criação. In: Minayo MCS, organizador. Pesquisa social: teoria, método e criatividade. Petrópolis: Editora Vozes; 1994. p. 51-66.

20. Geertz C. A interpretação das culturas. Rio de Janeiro: LTC Editora; 1989.

21. Deslandes SF, Gomes R. A pesquisa qualitativa nos serviços de saúde: notas teóricas. In: Bosi MLM, Mercado FJ, organizadores. Pesquisa qualitativa de serviços de saúde. Petrópolis: Editora Vozes; 2004 p. 99-120.

22. Cerveny C. A família como modelo: desconstruindo a patologia. São Paulo: Editora Livro Pleno; 2001.

23. Oliveira MLS, Bastos ACS. Práticas de atenção à saúde no contexto familiar: um estudo comparativo de casos. Psicol Reflex Crit 2000; 13:97-107.

24. Loyola MA. Médicos e curandeiros: conflito social e saúde. Rio de Janeiro: Editora Difel; 1984.

25. Souza MPL, Garnelo L. “É muito dificultoso!”: etnografia dos cuidados a pacientes com hipertensão e/ ou diabetes na atenção básica, em Manaus, Amazonas, Brasil. Cad Saúde Pública 2008; 24 Suppl 1:S91-9.

26. Helman CG. Cultura, saúde e doença. 4a Ed. Porto Alegre: Editora Artmed; 2003.

27. Velho G. Individualismo e cultura. 3a Ed. Rio de Janeiro: Jorge Zahar Editores; 2004.

28. Menéndez E. Modelos de atención de los padecimientos: de exclusiones teóricas y articulaciones prácticas. Ciênc Saúde Coletiva 2003; 8:185-208.

Recebido em 04/Ago/2009

Versão reapresentada em 31/Jan/2010

Aprovado em 22/Fev/2010 